\title{
The use of video technology for providing feedback to students: can it enhance the feedback experience for staff and students?
}

Article

Accepted Version

Crook, A., Mauchline, A., Maw, S., Lawson, C., Drinkwater, R., Lundqvist, K., Orsmond, P., Gomez, S. and Park, J. (2012) The use of video technology for providing feedback to students: can it enhance the feedback experience for staff and students? Computers \& Education, 58 (1). pp. 386-396. ISSN 0360-1315 doi: https://doi.org/10.1016/j.compedu.2011.08.025 Available at https://centaur.reading.ac.uk/23292/

It is advisable to refer to the publisher's version if you intend to cite from the work. See Guidance on citing.

Published version at: http://dx.doi.org/10.1016/j.compedu.2011.08.025

To link to this article DOI: http://dx.doi.org/10.1016/j.compedu.2011.08.025

Publisher: Elsevier

All outputs in CentAUR are protected by Intellectual Property Rights law, including copyright law. Copyright and IPR is retained by the creators or other copyright holders. Terms and conditions for use of this material are defined in the End User Agreement. 


\section{www.reading.ac.uk/centaur}

\section{CentAUR}

Central Archive at the University of Reading

Reading's research outputs online 


\section{Accepted Manuscript}

Title: The use of video technology for providing feedback to students: Can it enhance the feedback experience for staff and students?

Authors: Anne Crook, Alice Mauchline, Stephen Maw, Clare Lawson, Robyn Drinkwater, Karsten Lundqvist, Paul Orsmond, Stephen Gomez, Julian Park

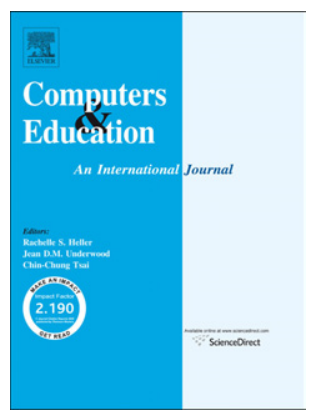

PII:

S0360-1315(11)00203-X

DOI: 10.1016/j.compedu.2011.08.025

Reference: CAE 1967

To appear in: Computers \& Education

Received Date: 25 May 2011

Revised Date: 13 August 2011

Accepted Date: 20 August 2011

Please cite this article as: Crook, A., Mauchline, A., Maw, S., Lawson, C., Drinkwater, R., Lundqvist, K., Orsmond, P., Gomez, S., Park, J. The use of video technology for providing feedback to students: Can it enhance the feedback experience for staff and students?, Computers \& Education (2011), doi: 10.1016/ j.compedu.2011.08.025

This is a PDF file of an unedited manuscript that has been accepted for publication. As a service to our customers we are providing this early version of the manuscript. The manuscript will undergo copyediting, typesetting, and review of the resulting proof before it is published in its final form. Please note that during the production process errors may be discovered which could affect the content, and all legal disclaimers that apply to the journal pertain. 


\section{ACCEPTED MANUSCRIPT}

The use of video technology for providing feedback to students: Can it enhance the feedback experience for staff and students?

Anne Crook $^{1}{ }^{*}$, Alice Mauchline ${ }^{2}$, Stephen Maw ${ }^{3}$, Clare Lawson $^{2}$, Robyn Drinkwater ${ }^{2}$, Karsten Lundqvist ${ }^{4}$, Paul Orsmond ${ }^{5}$, Stephen Gomez ${ }^{6}$ and Julian Park ${ }^{2}$

${ }^{1}$ Centre for the Development of Teaching and Learning, University of Reading, Whiteknights, Reading, RG6 6AA, UK.

${ }^{2}$ Department of Agriculture, University of Reading, Earley Gate, PO Box 237, Reading, RG6 6AR, UK.

${ }^{3}$ UK Centre for Bioscience, The Higher Education Academy, Room 9.15, Worsley Building, University of Leeds, Leeds, LS2 9JT, UK.

${ }^{4}$ School of Systems Engineering, University of Reading, Whiteknights, Reading, RG6 6AY, UK. ${ }^{5}$ Faculty of Sciences, Staffordshire University, College Road, Stoke-on-Trent, Staffordshire, ST4 2DE, UK.

${ }^{6}$ Work Based \& Placement Learning, Endsleigh Place, University of Plymouth, Drake Circus, Plymouth Devon, PL4 8AA, UK.

* Corresponding author: Anne Crook, Centre for the Development of Teaching and Learning, University of Reading, Whiteknights, Reading, RG6 6AA, UK. Tel: +44 (0)118 3787948; Email: a.c.crook@reading.ac.uk 
1

\section{Introduction}

2 Assessment and the provision of feedback are considered essential to student learning

3 (Biggs, 2003; Gibbs \& Simpson, 2004; Juwah, Macfarlane-Dick, Matthew, Nicol \& Smith,

4 2004; Sadler, 1983). Further, good quality and timely feedback are key features for

5 supporting effective student learning processes and in developing the student/tutor relationship (Irons, 2008). 'Feed-forward' forms an integral component of good quality feedback by signposting ways in which students may enhance their future performance (Duncan, 2007) and such developmental feedback is particularly valued by students (Lizzio \& Wilson, 2008). However, across the sector it has been recognised for some time that there are problems with the delivery of good quality, timely feedback; moreover, engaging students with assessment-related feedback poses additional challenges for staff (Bevan, Badge, Cann, Willmott, \& Scott, 2008). In recent years these problems have also been consistently highlighted in successive National Student Survey findings.

\subsection{Staff experience in delivering feedback}

For staff, the provision of feedback can be a very repetitive process and often very time consuming especially where class sizes are large. There is also evidence to suggest that feedback is not always as effective as staff imagine (Carless, 2006; Orsmond \& Merry, 2011) and Glover and Brown (2006) suggest that improvements can be made by shifting towards formative feedback, which can be defined as "the process used by teachers to recognise, and respond to student learning in order to enhance that learning, during learning" (Cowie \& Bell, 1999). There are also concerns at the lack of student engagement with the feedback process even when timely and good quality feedback is provided (Duncan, 2007). Staff sometimes find it difficult to provide appropriate feedback to large numbers of students and this problem may become worse if class sizes continue to grow. Further, with the shift to reliance on student fees for teaching and learning budgets in the UK, students may have their expectations of academic staff set higher than ever; for example, many students are already requesting the ability to submit work and receive feedback on-line (Hepplestone $\&$ Mather, 2007).

\subsection{Students' experience of receiving feedback}


For some students feedback can be provided in a manner which they feel is too late to be useful, too vague, unclear and inconsistent (Glover \& Brown, 2006; Weaver, 2006). Such sentiments have been highlighted by the National Student Survey (NSS) data which have shown that the overall area of 'assessment and feedback' in higher education has been consistently rated the lowest in terms of student satisfaction since the survey started in 2005 (Higher Education Funding Council for England [HEFCE] ${ }^{a}, 2010$; Surridge, 2008). Analysis of the longitudinal trends in these data have shown gradual improvements in students' perceptions of this area of their education (Kane \& Williams, 2008); possibly because $\mathrm{HE}$ institutions are acutely aware of these issues and have invested in a range of measures to try to improve feedback provision. However, the 2010 survey showed this area was still seen as problematic for students, particularly the issues of receiving prompt feedback and receiving feedback that helped clarify points in their work that they did not understand (HEFCE $\left.{ }^{b}, 2010\right)$.

\subsection{Audio and video feedback: Enhancing the feedback experience?}

Feedback has been known to be a challenge for both staff and students for some time, even before the introduction of the NSS. It is acknowledged that written feedback has its limitations (Price, 2007; Walker, 2009) including problems of illegible handwriting, and the potential for misunderstanding of the written comments. Although more personal, oral oneto-one feedback may not necessarily be perceived by students as feedback; indeed Smith (2007) has highlighted the concern that many students only see feedback as written comments on their assignments. With all the known challenges of providing feedback to students and helping them to engage more actively with their feedback a number of recent studies have looked at the pedagogic use of digital technologies for enhancing feedback provision. An appropriate technological application has the potential to encourage staff to reflect on their current feedback practices so that they can provide more detailed, comprehensible and engaging feedback. Technologies may also provide the innovative edge that can help students engage more effectively with their feedback.

Initial investigations into potential technological applications have included automated feedback from on-line tests (Wieling \& Hofman, 2010; Wilson, Boyd, Chen, \& Jamal, 2010) and feedback via the use of podcasts (Ribchester, France \& Wheeler, 2007) and audio MP3 
files (Lunt \& Curran, 2010; Merry \& Orsmond, 2008; Rotheram, 2009). The use of audio for feedback provision has been found to be of value to students (Nortcliffe \& Middleton, 2008) and can facilitate discussions between staff and students; Ribchester et al. (2007) argue that this type of feedback is most effective when utilised in conjunction with well designed assessment exercises. Merry \& Orsmond (2008) found that students appreciated audio feedback because it was perceived as being of good quality, was easier to understand, had more depth and was more personal than written feedback. Staff found audio feedback particularly valuable to explain complex ideas and by adjusting the volume or tone of their voice they could highlight specific points, and consequently more understanding could be gained from the spoken word than written text (Merry \& Orsmond, 2008).

Video has been used successfully in teaching and learning (Abdous \& Yoshimura, 2010; Bracher, 2005) and for peer feedback (Chi, Roy \& Hausmann, 2008). Further, Cann (2007) observes that short videos have a broad acceptance among students and can offer a much richer format for feedback provision than audio. For example, video recordings offer a powerful, visual way to provide feedback and there is some initial evidence that these technologies can augment student learning through the provision of formative feedback (Abrahamson, 2010; Cann, 2007; Rodway-Dyer \& Dunne, 2009). As video is a visual medium it has the potential to support learning in different ways to other technologies, including the potential for demonstrations (i.e. seeing as opposed to being told how to improve subsequent coursework (Abrahamson, 2010)) and through the use of screen-capture technology. A further advantage is that, like audio, video files provide a permanent record, which can be stored and replayed at the students' convenience.

\subsection{The ASSET project: Providing another way forward?}

The JISC-funded ASSET project was undertaken to develop a new Web 2.0 resource, 'ASSET', to explore the use of video as a means of enhancing the feedback experience for both students and staff. The project team designed ASSET as a 'Feedback Loop' to enhance student and staff engagement with feedback in a step-wise process. By designing ASSET as a feedback loop it set out the ways in which feedback can become 'feed-forward' into future work, thus hopefully maximising the benefits of feedback in terms of future performance. By engaging staff in the process of delivering feedback in a 'novel' way via brief video clips, it 
was anticipated this might trigger changes in the ways in which they both thought about and delivered feedback. Similarly, by receiving feedback in a novel, more dynamic way, it was hoped the students would better engage with the video feedback in comparison to more traditional methods.

\subsection{Aims}

This paper reports on one of the first systematic attempts to investigate the pedagogic potential of video to enhance engagement of staff and students with feedback processes across a range of disciplines. The emphasis was on investigating levels of staff engagement in terms of the extent to which video influenced their approaches to feedback and whether or not the use of video enhanced students' use of with feedback in comparison to the ways in which they would normally receive feedback. In particular, in this paper we aimed to:

- Establish the current methods of feedback delivery and to identify current issues/problems for staff and students;

- $\quad$ Assess whether video technology, as delivered via the ASSET resource, could address any of the issues raised and thereby enhance the feedback experience for staff and students.

\section{Methods}

\subsection{The ASSET resource}

In 2009 an online, interactive resource, 'ASSET', was developed by the project team using Web 2.0 approaches of interactivity and user-generated content and proprietary CORE software (Collaborative Online Resource for Education, Pentachoron, Sweden) (Gomez, 2009 The CORE software provided much of the functionality needed but required further development to include controlled access and search facilities. ASSET was therefore designed as a platform for storing the digital video files and was designed with a user interface and functionality to encourage staff to upload brief video files giving, in this first pilot phase, generic feedback to their students.

ASSET provided a user-friendly layout with a search facility; crucially however, there was controlled access to the resource via staff and students' normal University logins and 
passwords. The videos created by staff were made available in three distinct access levels (in a similar way to other video sharing sites, e.g. YouTube). There were 'University level' videos accessible by all staff and students at the University. These were general videos, for example, 'How to make the most of your feedback'. The next level, 'Module level' videos were accessible only to those students and staff associated with particular modules. Students were then able to create their own third level, 'My playlist', by selecting whichever of the University and Module-level videos they found most useful.

\subsection{Piloting the ASSET resource}

ASSET was made available to staff and students at the University of Reading for a trial period during 2009-10. Engagement of academic staff with the project was achieved by presenting briefing papers at Faculty Board teaching and learning meetings and through follow-up workshops led by the project team. In this way a wide range of staff from a number of disciplines (including Arts, Humanities, Business, Law, Life Sciences and Science) were recruited to the project. 'Top-down' support from senior management and IT support at the University, via a steering group, were central in ensuring staff were encouraged and supported to take part in the pilot study.

During the pilot study the ASSET resource was populated with brief (2-3 minute) videos by the academic staff and subsequently by other members of University staff (e.g. study advisers for University-level videos) over the course of the project. Staff were asked to trial the use of the ASSET resource for providing feedback to students as a way to supplement their other methods of feedback provision. In this trial staff were specifically asked just to provide generic feedback so that their involvement with the pilot project wasn't too onerous.

Each member of academic staff taking part was supplied with a webcam and the Department/School was supplied with a flip video ${ }^{\mathrm{TM}}$ (www.theflip.com) or camcorder and tripod to support the creation of videos in a wide range of contexts. Open source screen capture software, CamStudio ${ }^{\mathrm{TM}}$ (camstudio.org), was installed on staff computers and training and technical support were provided by the project team. The equipment and training were to enable staff to explore the use of screen-capture as a method for providing 
feedback to students i.e. 'on-screen' feedback. Staff were given free-reign to create their own choice and style of feedback videos.

\subsection{Staff \& student surveys}

In order to assess the potential pedagogic benefits of using video feedback, two different sets of questions were designed for staff; one set was completed before the use of the ASSET resource and one set was completed post-use. Two complimentary sets of questions were compiled to collect responses from students. The questionnaires were developed using Bristol Online Survey software (BOS) and the survey link was emailed to all staff engaged with the project and the students registered on their modules. The questionnaires included open format and five-point 'Likert' scale questions and were cleared by an Ethics Committee prior to release. The project website www.rdg.ac.uk/videofeedback contains the original questionnaires (under Project Pedagogy). The project Final Report contains detailed findings from these surveys and reports on the mechanics of using the ASSET resource (Crook et al., 2010).

The pre- and post-use questionnaires were analysed separately and no direct comparisons were made between these two sets of data. The pre-use questionnaires aimed to collate data relating to the views, preferences, understanding and experience of current assessment and feedback practices of both staff and students. The staff questionnaire comprised 25 questions that gathered background information on staff involved in the project and about their experiences of providing feedback including; their views and current practices, the challenges they face and their initial thoughts on using video for feedback. The student questionnaire comprised 18 questions that gathered background information and explored their views and experiences of feedback, what they do with their feedback and the types of feedback they prefer.

The staff post-use questionnaire comprised 15 questions which focused on the use of the ASSET resource; how many and what type of videos the staff had uploaded, how long they took to create the videos, whether or not they would use video again for feedback provision and whether the use of video had changed their approach to feedback provision. The student post-use questionnaire comprised 21 questions which focused on whether they liked the provision of feedback via video and if they found it useful in comparison to other 
generic feedback methods, how they used the feedback and whether they would like staff to keep using video for providing feedback.

\section{Results}

\subsection{Overview of survey participants}

Background information about the staff and student participants in the surveys are summarised in Table 1.

Pre-use: Replies were received from 27 staff; there was a roughly equal male:female ratio (48\%:52\%) and they represented all Faculties across the University (including Arts \& Humanities, Business School, Life Sciences, Science and Economic \& Social Science). Replies were received from 287 students; there were more female respondents (71\%) than males (29\%). The students were at varying stages in their degree programmes ranging from foundation through first to fourth year undergraduates and some postgraduates.

Post-use: Replies were received from 8 staff and 105 students. There were fewer responses to the post-use questionnaires than the pre-use questionnaires, which is a common problem with questionnaire data collection. Some of the reduction in participants (staff and student) was due to technical problems, particularly in the Arts \& Humanities Faculty, which have now been resolved by embedding the ASSET resource into the University's Virtual Learning Environment. Overall however, the pilot study was still conducted by sufficient staff and students to make it a valid trial of a novel approach to feedback provision across the University.

\subsection{Current issues for staff in providing feedback to students (results from the pre-use} questionnaire)

Prior to using ASSET staff reported that they used a range of methods to provide feedback to students including written (92.6\%), oral, e.g. formal and informal comments given in classes/tutorials (88.9\%) and face-to-face feedback (59.3\%). Less than $10 \%$ used email, audio, and video methods. Written feedback was used most often by staff members and they also considered it to be the students' most preferred method. Staff mainly used written feedback as they stated this was 'what was expected' from them (25.9\%) or because 
it was the 'easiest/most direct' (14.8\%), while $11.1 \%$ stated it was the 'most suitable' or because it 'provides a permanent record'.

The amount of time and effort staff spent providing feedback was found to vary considerably; most spent less than $10 \%$ of their working week, but some spent over $50 \%$ of their time on feedback provision. However all staff acknowledged that their methods of feedback could be improved. Most staff (84.6\%) made attempts to monitor the effectiveness of their feedback, for example, by checking for changes/improvements in students' subsequent work (34.6\%) or through feedback forms/follow-up sessions with students (26.9\%).

Staff listed concerns they had about providing feedback to students and these predominantly fell into four main categories (staff could list more than one concern):

- Engagement: Making sure that students understand and engage (i.e. actively make use of) the feedback provided;

- Efficiency: Using staff time in an efficient manner to generate quality feedback;

- Timeliness: Returning the feedback in a timely manner (i.e. in a timeframe that enables students to enact on the feedback for a future assignment);

- Quality: Providing understandable feedback that gives students the opportunity to use it for their learning and improvement in subsequent assignments.

\subsection{Current issues for students in receiving feedback (results from the pre-use questionnaire)}

The students expressed a preference for written feedback returned with their work and for feedback through one-to-one discussions with staff, whereas audio/video feedback was the least common and least preferred method prior to the use of the ASSET resource (Table 2). However, students were able to articulate the importance of feedback to their learning; of those students that had already completed at least one year's study $84.9 \%$ stated that feedback had been important during their previous year of study.

Students were asked what they normally did with their feedback, which is summarised in Table 3. Most stated that they read the written comments on their assignments and often read them more than once, with fewer students stating that they discuss their feedback with others or go to see the person who set the work. Table 4 summarises the main ways in 
which students' stated they'd made use of feedback with $95.4 \%$ of them stating that they use the feedback they receive on their work; $47 \%$ of the students used feedback to inform future pieces of work while $20.6 \%$ used it to understand the good/bad points in their work. However, the students were generally less happy with certain aspects (mainly the quality) of the feedback they received (Table 5). As shown in Table 5, the students were happy to use feedback to evaluate their current work and to work effectively in later assignments, but they stated that their feedback failed to make it clear exactly how to improve their future performance and how to think differently about how they worked.

Some students (22.9\%) stated that they regularly go to see the member of staff who set their coursework to discuss their feedback. Their main reasons for going were to better understand what was said/written by them (37.6\%) and to seek advice on how to improve their performance (40.4\%). Of those students that tended not to talk with staff about their coursework and feedback, the overriding reason given was that the students felt uncomfortable approaching academic staff (75\%).

\subsection{Staff experiences of using video for feedback provision (results from the post-use questionnaire)}

During the ASSET pilot staff each uploaded an average of five videos (the range was 2-20 videos). Most video clips were of the 'talking head' style (87.5\%), while half of the staff also used screencasts and one used it for voice casts. Seven out of the eight members of staff who completed the post-use survey enjoyed using video and all would consider using video again for feedback provision. The majority (87.5\%) said they would use it again for providing generic feedback or feedback to small groups (37.5\%) (Fig. 2) and all but one would recommend to colleagues using video for feedback provision.

Staff identified advantages of video feedback, namely that videos can be re-viewed, are accessible, like a one-to-one session and students took more notice of them; one of the main challenges identified by staff was that it took a long time to get familiar with and use the ASSET resource (Table 6). The following points, centred around the main issues of engagement, efficiency, quality and timeliness show how the data gathered on staff experiences of video feedback can provide evidence of how video technology might/not 
address the problems that staff had identified with feedback provision prior to using the ASSET resource:

Engagement of students: The general perception was that students took a similar amount of notice of the video feedback as they did to the normal mechanisms of feedback. On a scale of 1 (much more notice) to 5 (much less notice) the median response was $3(n=8)$ with an inter-quartile range of 1 . However, the data from the student survey showed that students felt that they did take more notice of the generic video feedback in comparison to other forms of generic feedback (Section 3.5).

Efficiency: Each video took most staff less than 10 minutes to produce but in one instance it took over 30 minutes. However, in general, video was found to take a similar amount of time to other methods of generic feedback provision. On a scale of 1 (video was much more time consuming) to 5 (video was much less time consuming) the median response was $3.5(n=8)$ with an inter-quartile range of 1.5 .

Timeliness: Two of the main advantages of video highlighted by staff included the speed at which the feedback (and feed-forward) could be provided and it's accessibility; meaning that the students could access the feedback as soon as it has been uploaded. The main advantage cited by staff (Table 6) is that video feedback can be re-played, therefore allowing students to quickly access the feedback/feed-forward when completing a similar piece of work in the future.

Quality: A significant pedagogic finding from the ASSET pilot was that the majority of staff $(75 \%)$ replied that the use of video had positively changed their approach to feedback provision. Staff quotes from the questionnaires revealed these changes: "I have more sympathy with those students who struggle with written forms of feedback, and try to emphasise the principal things rather than lose these in the detail"; "it opened up my mind generally to alternative forms of feedback".

\subsection{Student experiences of receiving feedback via video (results from the post-use questionnaire)}

$80 \%$ of the students liked the use of video as a way of receiving feedback and they detailed the ways in which they would like their lecturers to continue using it (Fig 2), for example, for 
feedback to small groups (51.4\%) or for generic feedback (47.6\%), but 31.4\% thought it would work also for one-to-one feedback provision. Quotes from the post-use student questionnaires included: "I could engage better, absorbing more information with video feedback"; "it was very concise and useful at anytime for reference"; "provides a quick and accessible means for feedback"; "meant the lecturer could give clearer, more in-depth feedback".

Engagement: Students indicated that they had actively engaged with the feedback videos, with many of them discussing the video feedback with other students (58.1\%). Some viewed the videos with their peers (13.3\%) and 61\% reported viewing the same video more than once (one student watched the same video six times). An important finding was that $60 \%$ of the students said that receiving video feedback had encouraged them to take more notice of the feedback compared to normal methods of generic feedback provision. Examples of how the students stated that they'd used the video feedback are given in Table 4.

Quality: The main advantage of video cited by students was that the feedback provided was easy/clear to understand in comparison to normal methods of feedback provision (e.g. written, oral). Further, they suggested that the feedback was more extensive, informative, the key points were better emphasised and that it aided their visualisation of the task through demonstrations and/or diagrams.

The students identified a number of other advantages of receiving feedback by video (Table 6) but also cited various disadvantages. Most of these focussed on the issues of receiving generic feedback rather than individual feedback along with some of the technical 'snagging' difficulties that were encountered when first using the ASSET resource, for example, slow download of video files on some computers.

\section{Discussion}

\subsection{The status quo}

Staff are under pressure to provide high quality feedback to students in a prompt manner, often to large and diverse cohorts. Increasingly institutions are facing significant staff resourcing issues and coupled with changes in the nature of students' expectations of 
Higher Education, the need to enhance feedback processes is ever more pressing. The provision of feedback to students is both a core element of the learning process (Hattie \& Timperley, 2007) and of the teaching responsibilities of staff, but it can easily become very time-consuming especially in the face of other pressures on staff time.

This study includes staff that, although self-selected, represent a broad range of subject areas, teaching experiences and student cohort sizes. The results showed that prior to using video these staff used a range of methods for feedback provision, including written, oral, on-line quizzes, peer-review and email. These approaches were used for a variety of reasons, including because that 'what was expected' of them by students or because they were the easiest/quickest methods to generate feedback. This latter reason is particularly pertinent given the increase in student numbers on individual modules and the increases in the student:staff ratio (Association of University Teachers [AUT] Research, 2005; Fowler, 2005) but it clearly has implications for student support, learning and progression, for example, with large student cohorts it is difficult for staff to provide high quality, tailored feedback for each individual student.

The results of the ASSET pilot showed that the students' most preferred methods of feedback match those methods most frequently used (Table 2). This may be due to an actual preference or possibly just familiarity; whichever of these it is, current methods seem to be providing the students with information about good/bad points in the marked piece of work (Table 5). These findings are encouraging; however, it is important for students to become self-regulated learners (Boud \& Falchikov, 2006; Nicol \& Macfarland-Dick, 2006) and to understand the meaning of their feedback in relation to their work in general (Sadler, 2010) and start to use that information to improve (Orsmond et al., in press; Sadler, 1989). This does not come easily to all learners (Chanock, 2000; Weaver, 2006) and our data showed that a significant number of students were not necessarily using their feedback in the most effective ways (Table 5). In order to help this process, students need good quality feedback promptly after submission of the work (Huxham, 2007). Ideally, they require this before starting their next piece of coursework, with elements of feed-forward to allow them to focus their efforts appropriately to improve their future performance (Duncan, 2007; Gibbs \& Simpson, 2004). 


\subsection{Suggestions for improvements to current practice}

352 The main issues with feedback provision as identified by staff were not surprising student engagement, time efficiency and the provision of good quality feedback in a timely manner. The provision of a rapid, generic, response to all students is one way for staff to resolve some of these issues prior to the provision of individual, tailored feedback. After quickly skim-reading a cohort's work the key points that were done well/badly are usually apparent, so if these can be quickly identified and promptly relayed to the students, for example in a brief video, students are then able to utilise this information in advance of completing the next assignment. Provision of prompt, generic feedback to sum up the best/not-so-good elements of the 'class performance' often provides 'enough for now' information to enable the students to progress with their studies while staff undertake the more time-consuming task of providing individual feedback.

\subsection{Can video technology help staff to improve current feedback practices?}

The provision of generic feedback was considered to be one of the main ways in which both staff and students could envisage video technology being advantageous (Fig. 2). Certainly, a number of the comments made by staff on the use of video related to the ability to produce rapid, generic video clips: "has made giving generic feedback quicker"; "generic feedback can be provided directly and just as efficiently"; "generic comments for feedback and feedforward were easy to communicate to large groups"; "it allowed very quick, generic, accessible and impressionistic feedback to be given". The use of video can also be extremely effective to articulate assessment criteria when an assignment is set, i.e. to spell out what makes a good/not-so-good poster, presentation or report etc. The advantage of video is that these pre-assignment clips can be re-played as students prepare their work and they may also be re-used by staff in a variety of contexts.

By providing many of the key messages to all students in one generic video, it has potential to make the process of producing individual feedback more efficient as the main points have already been covered, thus allowing more time for staff to spend on delivering tailored feedback to individual students. It can also enhance the experience for staff by removing some of the repetitive element of feedback provision by saying all those points in a single, all-encompassing video. 
Planning is an important element of creating video files (Abrahamson, 2010). By thinking about the generic feedback and identifying 'signposts' before recording a video, staff can produce a structured response to help highlight what was expected (feedback) and what is expected to improve future performance (feed-forward). This 'time for thought' has important implications for the quality of the feedback. By providing a new medium for feedback provision, most staff in this study found that the use of video had prompted them to think how to use the feedback opportunity more wisely and to think more broadly about feedback processes. This could avoid the recognised problem with repetitive written feedback where a large number of comments are 'unlikely to be useable' in helping students understand how to improve (Walker, 2009). This difference in approach by staff evidently had an effect on the students in this study as $60 \%$ of students reported taking more notice of video feedback than other generic feedback methods. This is important evidence that video can have an impact on student engagement with feedback and if it can be achieved at a generic level, this is encouraging for the use of video for individual feedback (where practical and where resources permit).

\subsection{Will students benefit?}

Following the ASSET pilot $80 \%$ of students reported liking the use of video feedback; however it was interesting to note that video was the least preferred feedback method for students prior to the use of the ASSET resource, perhaps because they had not yet experienced the full potential of such technologies in feedback provision. Although some students (17\%) disliked video feedback because it was 'generic' or deemed to be impersonal, the majority seemed to appreciate how video could provide generic feedback in a more engaging way. Staff could articulate assessment criteria and key points in a clear fashion with video, thereby overcoming misinterpretations of written feedback and problems of reading illegible handwriting. Pre-assignment videos were popular with staff and can be made available at the time the assignment is set and crucially can be replayed by students. The pilot study showed that video clearly satisfied the students' expectations for feedback to be understandable/clear as this was listed as their top advantage of video feedback (Table 6). 
Staff described the use of video as "like a face-to-face session" and students also felt the same way "it felt like I was getting advice in the first person". Students also appreciated the emotive aspects of video; "it was easier to gauge the reaction and emphasis of a lecturer by watching a video than it was through written feedback" and "watching and listening to someone speak says more than reading feedback". The personal aspect of video feedback may also help to break down any real or perceived barriers between students and staff and this has considerable potential when dealing with part-time or overseas students. One of the problems highlighted in the pre-use data was that many students don't tend to go to see their tutor to ask further questions about feedback they have received (Table 3). There are many reasons for this including a reluctance to approach an academic member of staff. Video has the potential to overcome these concerns as the member of staff is clearly identifiable and it can also help portray staff in a more informal context. In addition, individuals vary in their learning styles (Kolb, 1984) and by using a mixture of visual (video) and other feedback methods a broader range of learners can be supported.

Receiving prompt feedback is important in student learning and, as discussed, the ASSET resource provided a way for staff to generate and rapidly disseminate generic feedback (and indeed individual feedback in some instances where class sizes were small). Since the videos are available online, students can access their feedback remotely and on-demand without having to travel into University. The feedback can also be viewed at the most convenient time and place for the learner; this flexibility was another of the major advantages of video that students identified, along with the ability to be able to re-play videos when required. Such flexibility is now becoming more viable as techniques, such as live-video streaming, are able to deliver extended learning opportunities to 'non-traditional' students (Abdous \& Yoshimura, 2010).

Students are very receptive to new types of information and computing technology and there is a real opportunity for Web 2.0 technologies to impact on learning (JISC, 2008). ASSET was constructed using Web 2.0 approaches of interactivity and user-generated materials to provide a way to facilitate and enhance feedback provision. As part of this, students had the opportunity to post comments on the generic video feedback they received, thereby completing the 'feedback loop' (Fig. 1). However, the students were not 
required to do this during the pilot, but with encouragement this facility could provide an important 'missing link' in the feedback dialogue process between staff and students. For instance, students could be asked to post comments in response to a given video as a basis for discussions in a following class, or as a pre-requisite to a subsequent assignment.

Encouraging such dialogue (Nicol, 2010; Carless, 2006) would concur with findings from a recent survey of the use of technology in feedback which concluded that "the availability of feedback stored online for future reference augmented by the opportunity for, and expectation of, further dialogue provides the greatest benefit to future learning" (Hepplestone, Parkin, Holden, Irwin \& Thorpe, 2009). Resources like ASSET, when embedded into a virtual learning environment (VLE), can provide a platform for students and staff to engage with feedback as a dialogue and ultimately should provide beneficial impacts on student learning.

\subsection{Potential pitfalls and opportunities for further research}

As with most pedagogic innovations, the impact of video feedback is affected by individual preferences; some students found it a more personal way to receive feedback "it's like having a one-to-one meeting with the lecturer" while others felt the opposite "..depersonalises the feedback experience". Also, it is possible that the interest and engagement of staff and students in the use of video for feedback provision may have been affected by its novelty value. However, this is true for any innovation and is not restricted to the use of video technologies.

Some of the main disadvantages articulated by students of receiving video feedback were a range of technical problems associated with the use of the ASSET resource itself (Table 6). Navigation of the site, slow loading videos, poor video/sound quality plus a range of other technical problems were all cited as disadvantages. However, the development of new technologies, refinement of the user interface and increasing bandwidth capacity is likely to reduce some of these technical access issues. Such problems are inherent in the early developmental phase of new technologies and further development of the use of video for feedback is being integrated within the University's virtual learning environment, Blackboard $^{\mathrm{TM}}$. In this way, videos can be embedded within module learning materials, 
making it much easier for staff and students to navigate as they are already familiar with the VLE whilst also avoiding the types of compatibility problems that were encountered during the pilot trial of the ASSET resource.

Brown (2007) states that "giving students detailed and developmental formative feedback is the single most useful thing we can do for our students". With the NSS and other student 'drivers' continuing to put assessment and feedback in the limelight, it is important that additional pedagogic research takes place to assess the role of video (and indeed other technologies) in enhancing feedback provision for students. This could be achieved, for example, by conducting an intervention study similar to Wilson et al. (2011) to examine whether the individual performances of students that received video feedback are significantly improved in comparison to when they receive other forms of feedback on the same type of assignment.

\section{Conclusions}

Piloting the ASSET resource for using video to provide feedback to students provided a new approach to engage staff and students in the feedback process. The study highlighted how the use of video can potentially solve some of the existing problems with feedback provision, namely issues of student engagement with feedback, time-efficiency for staff, timeliness and quality of feedback received by students. Indeed, video feedback has the potential to meet many of the requirements for effective feedback as outlined by Gibbs \& Simpson (2004). Importantly, this study has revealed that the use of video instigated positive changes in the ways in which staff thought about and developed feedback for their students; and for students, the use of video enhanced their active engagement with the feedback they received. Following the pilot study the majority of staff and students surveyed would like to continue to use video as a method of feedback provision, which has been used to inform the development of video embedding within the institution's VLE.

\subsection{So, does the use of video enhance the feedback experience?}

The data in this study indicate that the use of video can enhance both staff and students' respective feedback experiences. Moreover, video technology has the potential to improve opportunities for students to benefit from remotely-accessible feedback that they might 
501

otherwise miss; this could be especially important for part-time, over-seas and distance

502 learners. Furthermore, this study has shown that video can be used for both generic and

503 individual feedback (the latter however, only being practicable where staff: student ratios 504 are low and/or where resources allow).

\section{References}

506 Abrahamson, E. (2010). Assessment through video-feedback on an undergraduate sports 507 rehabilitation programme. Higher Education Academy [HEA] Case Study. Retrieved 508 fromhttp://www.heacademy.ac.uk/assets/hlst/documents/case studies/147 abrahamson $509 \quad$ video-feedback.pdf

510 Abdous, M. \& Yoshimura, M. (2010). Learner outcomes and satisfaction: A comparison of 511 live video-streamed instruction, satellite broadcast instruction, and face-to-face instruction. 512 Computers \& Education, 55, 733-741.

513 Association of University Teachers [AUT] Research (2005). Packing them in - The student-to514 staff ratio in UK higher education. Retrieved from

515 http://www.ucu.org.uk/media/pdf/c/i/ssr packingthemin.pdf

516 Bevan, R., Badge, J., Cann, A., Willmott, C. \& Scott, J. (2008) Seeing eye-to-eye? Staff and 517 student views on feedback. Bioscience Education, 12, 1.

518 Biggs, J. B. (2003). Teaching for quality learning at university: what the student does. Society 519 for Research into Higher Education \& Open University Press, Maidenhead, UK.

520 Boud, D. \& Falchikov, N. (2006). Aligning assessment with long-term learning. Assessment 521 and Evaluation in Higher Education, 31, 399-413.
Brown, S. (2007). Feedback \& feed-forward. Centre for Bioscience Bulletin, 22, 1.

Bracher, M., Collier, R. Ottewill, R., \& Shephard, K. (2005). Accessing and engaging with video streams for educational purposes: experiences, issues and concerns. $A L T-J$, Research in Learning Technology 13, (2), 139-150.

Cann, A. J. (2007). Podcasting is dead. Long live video! Bioscience Education, 10, (C1). 
Carless, D. (2006). Differing perceptions in the feedback process. Studies in Higher Education, 21, 219-233.

Chanock, K. (2000). Comments on essays: do students understand what tutors write?

Teaching in Higher Education, 5, 95-105.

Chi, M. T. H., Roy, M. \& Hausmann, R. G. M. (2008). Observing dialogues collaboratively: Insights about human tutoring effectiveness from vicarious learning. Cognitive Science, 32, 301-341.

Cowie, B., \& Bell, B. (1999). A model of formative assessment in science education. Assessment in Education, 6, 101-116.

Crook, A. C., Park, J. R., Lawson, C. S., Lundqvist, K. O., Drinkwater, R., Walsh, J., Gomez, S., Orsmond, P. and Maw, S. J. (2010). ASSET: Moving Forward Through Feedback. Joint Information Systems Committee [JISC] Final Report. Retrieved from http://www.reading.ac.uk/web/FILES/asset/ASSET final report.pdf

Duncan, N. (2007). 'Feed-forward': improving students' use of tutors' comments.

Assessment and Evaluation in Higher Education, 32, 271-283.

Fowler, G. (2005). An analysis of Higher Education staff attitudes in a dynamic environment FORUM - The Arena for Discussion and Reflection on Current Issues in Higher Education.

Tertiary Education and Management, 11, 183-197.

Gibbs, G. \& Simpson, C. (2004). Conditions under which assessment supports students' learning. Learning and Teaching in Higher Education, 1, 3-31.

Glover, C. \& Brown, E. (2006). Written feedback for students: too much, too detailed or too incomprehensible to be effective? Bioscience Education, 7,3 .

Gomez, S. (2009). A report on the software system for ASSET. Retrieved from http://www.reading.ac.uk/web/FILES/asset/Appendix 1 final report ASSET IT Report.pdf

Hattie, J. \& Timperley, H. (2007). The power of feedback. Review of Educational Research, 77, (1), 81. 
Hepplestone, S. \& Mather, R. (2007). Meeting rising student expectations of online assignment submission and online feedback'. Proceedings of the 11th International Computer-Assisted Assessment Conference 2007, Loughborough, 10-11 July 2007. Retreived from

http://www.caaconference.co.uk/pastConferences/2007/proceedings/Hepplestone $\% 20$ S\%2 OMather\%20R\%20n1 formatted.pdf

Hepplestone, S., Parkin, H., Holden, G., Irwin, B. \& Thorpe L. (2009). Technology, Feedback, Action!: Impact of learning technology on students' engagement with feedback. HEA Final Report.

Higher Education Funding Council for England [HEFCE] ${ }^{a}$ (2010). National Student Survey. Findings and trends 2006 to 2009. HEFCE Report. Retrieved from www.hefce.ac.uk/pubs/hefce/2010/10 18/

HEFCE $^{\mathrm{b}}$ (2010). NSS 2010 shows continued high levels of satisfaction among higher education undergraduate students. HEFCE News. Retrieved from www.hefce.ac.uk/news/hefce/2010/nssresult.htm

Huxham, M. (2007). Fast and effective feedback: are model answers the answer? Assessment and Evaluation in Higher Education, 32, 601-611.

Irons, A. (2008). Enhancing learning through formative assessment and feedback. Key Guides for effective teaching in Higher Education. Abingdon, UK: Routledge.

Juwah, D., Macfarlane-Dick, B., Matthew, D., Nicol, D. \& Smith, B. (2004). Enhancing student learning through effective formative feedback. The Higher Education Academy, York, UK. Joint Information Systems Committee [JISC] (2008). Great Expectations of ICT: How Higher Education Institutions are measuring up. JISC Report. Retrieved from www.jisc.ac.uk/media/documents/publications/jiscgreatexpectationsfinalreportjune08.pdf Kane, J. \& Williams, D. (2008). Exploring the National Student Survey. Assessment and feedback issues. HEA Report. Retrieved from www.heacademy.ac.uk/assets/York/documents/ourwork/nss/NSS Assessment and Feedb ack_ExecSummary 31.04.08.pdf 
Kolb, D. (1984). Experiential learning: Experience as the source of learning and development. Englewood Cliffs, NJ: Prentice-Hall.

Lizzio, A. \& Wilson, K. (2008). Feedback on assessment: students' perceptions of quality and effectiveness. Assessment and Evaluation in Higher Education, 33, 263-275.

Lunt, T. \& Curran, J. (2010). 'Are you listening please?' The advantages of electronic audio feedback compared to written feedback. Assessment and Evaluation in Higher Education, 35, 759-769.

Merry, S. \& Orsmond, P. (2008). Students' attitudes to and usage of academic feedback provided by audio files. Bioscience Education, 11, 3.

Orsmond, P. \& Merry, S. (2011). Feedback alignment: effective and ineffective links between tutors'and students' understanding of coursework feedback. Assessment and Evaluation in Higher Education, 36, 125-136.

Orsmond, P., Maw, S. J., Crook, A. C., Park, J. R., Gomez, S., Drinkwater, R., Lawson, C. \& Lundqvist, K. O. (In press) Moving feedback forward: theory to practice. Assessment and Evaluation in Higher Education.

Price, M. (2007) Should we be giving less written feedback? Centre for Bioscience Bulletin, $22,9$.

Nicol, D. (2010). From monologue to dialogue: Improving written feedback processes in mass higher education. Assessment and Evaluation in Higher Education, 35, 501-517.

Nicol, D. J. \& Macfarlane-Dick, D. (2006). Formative assessment and self-regulated learning: a model and seven principles of good feedback practice. Studies in Higher Education, 31, 199-218.

Nortcliffe, A., \& Middleton, A. (2008). A three year case study of using audio to blend the engineer's learning environment. Engineering Education, 3 (2), 45-57.

Ribchester, C., France, D. \& Wheeler, A. (2007). Podcasting: a tool for enhancing assessment feedback? Education in a Changing Environment, Volume 4, Salford University, 12-14 September 2007. Informing Science, 131-139. 
608

Rodway-Dyer, S. \& Dunne, E. (2009). Technology enhanced feed-forward for learning. HEA

Final Report. Retrieved from http://www.heacademy.ac.uk/assets/EvidenceNet/Exeter.doc

Rotheram, B. (2009). Sounds Good. JISC Final Report. Retrieved from

http://www.jisc.ac.uk/publications/reports/2009/soundsgoodfinalreport.aspx

Sadler, D.R. (1983). Evaluation and the improvement of academic learning. Journal of Higher Education, 54, 60-79.

Sadler, D.R. (1989). Formative assessment and the design of instructional systems. Instructional Science, 18, 119-144.

Sadler, D.R. (2010). Beyond feedback: developing student capability in complex appraisal. Assessment and Evaluation in Higher Education, 35, 535-550.

Smith, B. (2007). Is assessment really for learning? Centre for Bioscience Bulletin, 22, 11.

Surridge, P. (2008). The National Student Survey 2005-2007: Findings and Trends. HEFCE

Report. Retrieved from www.hefce.ac.uk/pubs/rdreports/2008/rd12 08/rd12 08.pdf

Walker, M. (2009). An investigation into written comments on assignments: do students find them usable? Assessment and Evaluation in Higher Education, 34, 67-78.

Weaver, M. R. (2006). Do students value feedback? Student perceptions of tutors' written responses. Assessment and Evaluation in Higher Education, 31, 379-394.

Wieling, M. B. \& Hofman, W. H. A. (2010). The impact of online video lecture recordings and automated feedback on student performance. Computers \& Education, 54 (4), 992-998. doi: 10.1016/j.compedu.2009.10.002

Wilson, K., Boyd, C., Chen, L. \& Jamal, S. (2011). Improving student performance in a firstyear geography course: Examining the importance of computer-assisted formative assessment. Computers \& Education, 57, (2), 1493-1500.

doi:10.1016/j.compedu.2011.02.011 
1
Figure 1. The ASSET 'Feedback Loop'; showing the design of the ASSET video feedback

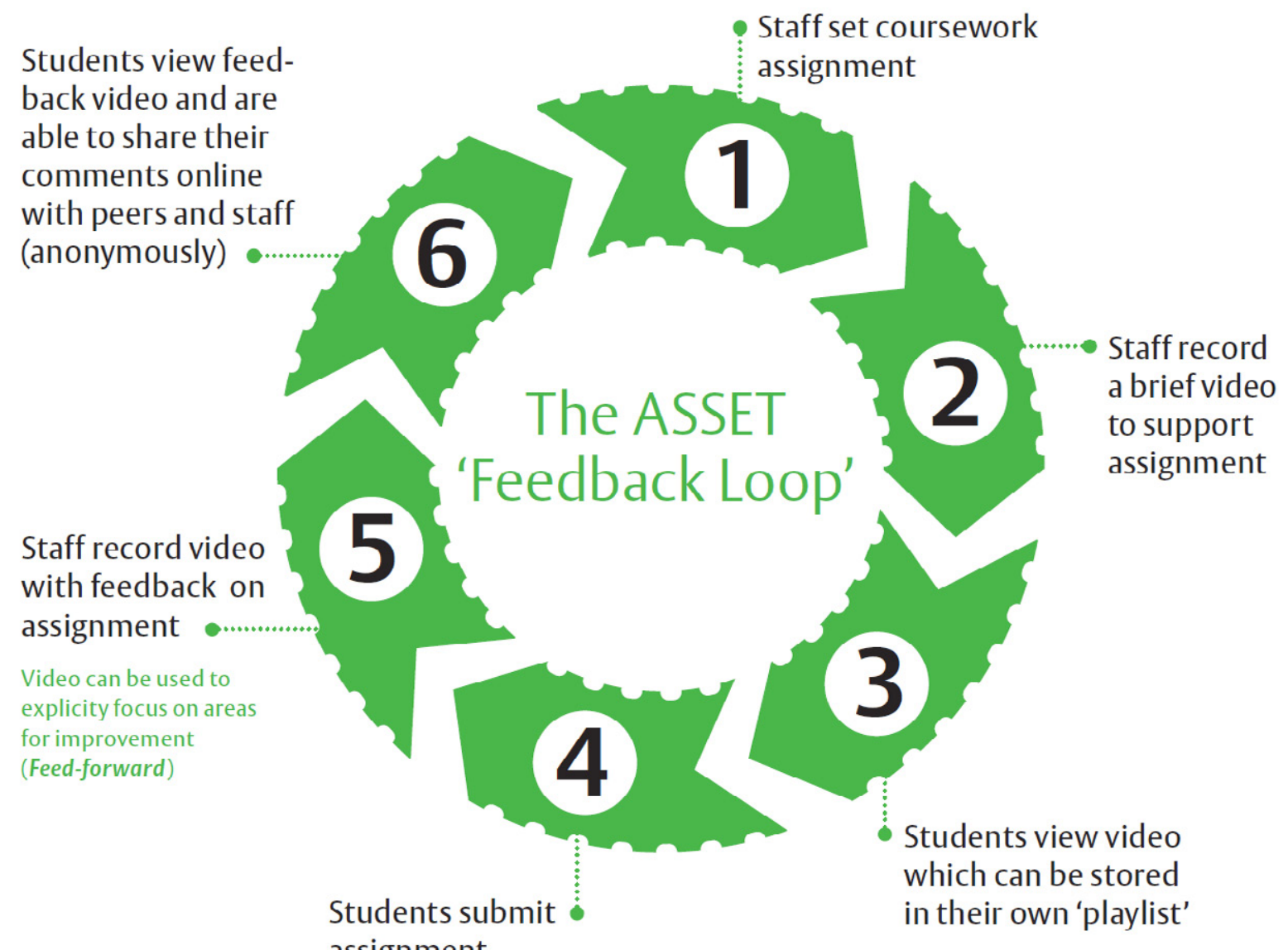


637 Figure 2. Ways in which staff $(n=8)$ and students $(n=105)$ would like to continue the use of video technology for feedback provision. Numbers refer to numbers of individuals 639 (individuals could choose more than one option). 'Other' suggested uses included the 640 provision of feed-forward, supplemental lecture information and exam tips.

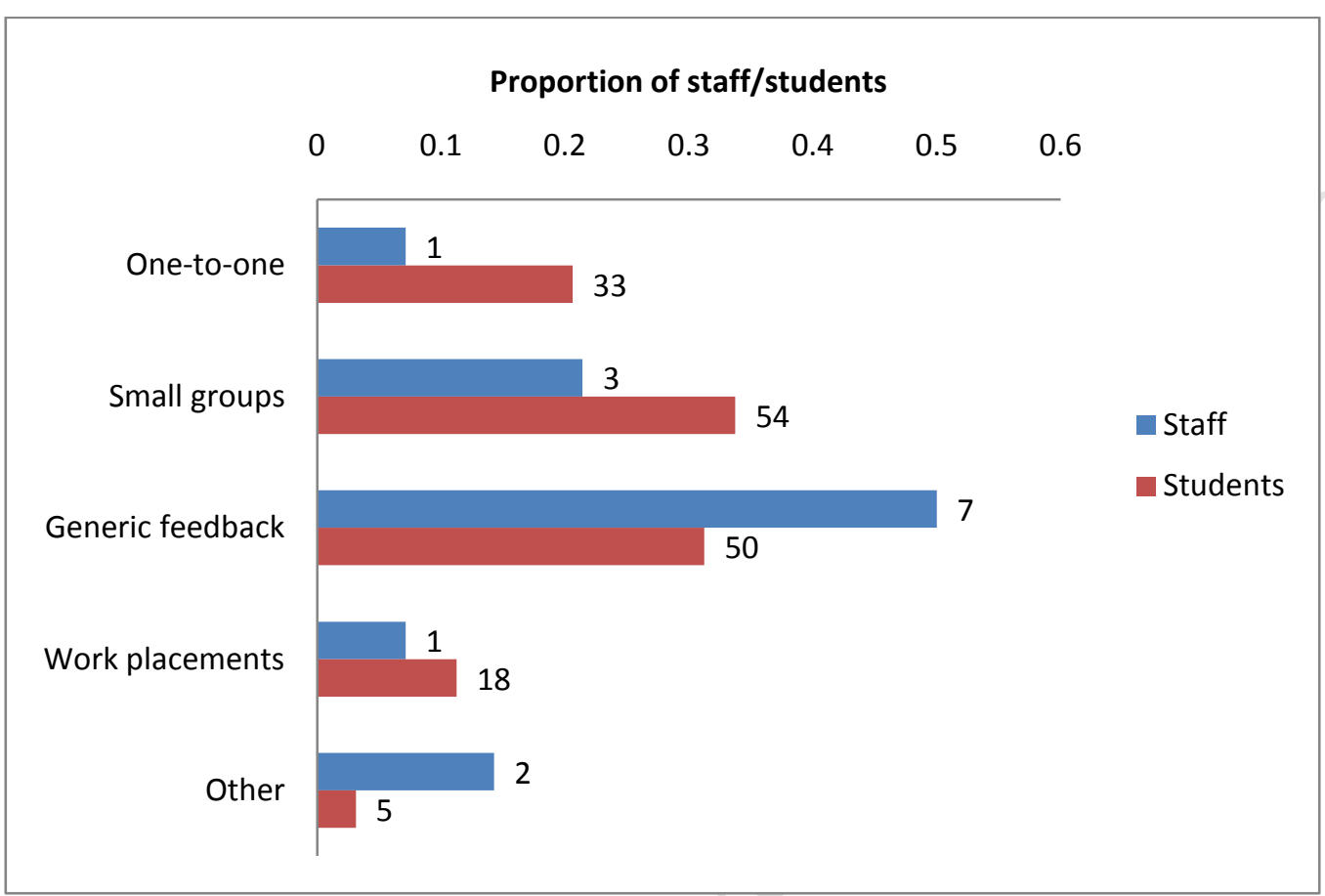


1

644 Table 1. Profiles of the staff and students engaged with the ASSET pilot study.

\begin{tabular}{|c|c|c|c|c|c|}
\hline \multirow{2}{*}{\multicolumn{2}{|c|}{ Category }} & \multicolumn{2}{|c|}{ Pre-use survey } & \multicolumn{2}{|c|}{ Post-use survey } \\
\hline & & Frequency & Percentage & Frequency & Percentage \\
\hline \multicolumn{6}{|c|}{ Staff } \\
\hline \multicolumn{6}{|c|}{ Gender } \\
\hline- & Male & 13 & $48.1 \%$ & & \\
\hline - & Female & 14 & $51.9 \%$ & & \\
\hline \multicolumn{6}{|c|}{ Years teaching at the University } \\
\hline- & $0-1$ years & 2 & $7.4 \%$ & & \\
\hline- & $2-5$ years & 8 & $29.6 \%$ & & \\
\hline- & $6-10$ years & 9 & $33.3 \%$ & & \\
\hline- & $11+$ years & 8 & $29.6 \%$ & & \\
\hline \multicolumn{6}{|c|}{ Faculty } \\
\hline- & Arts \& Humanities & 10 & $37.0 \%$ & 0 & $0 \%$ \\
\hline- & Henley Business School & 6 & $22.2 \%$ & 1 & $12.5 \%$ \\
\hline- & Life Sciences & 6 & $22.2 \%$ & 3 & $37.5 \%$ \\
\hline- & Science & 2 & $7.4 \%$ & 1 & $12.5 \%$ \\
\hline- & Social Sciences & 2 & $7.4 \%$ & 3 & $37.5 \%$ \\
\hline- & Not attached to a Faculty & 1 & $3.7 \%$ & 0 & $0 \%$ \\
\hline \multicolumn{6}{|c|}{$\begin{array}{l}\text { Confidence in using computer technology } \\
\text { in teaching }\end{array}$} \\
\hline- & Always & 6 & $22.2 \%$ & & \\
\hline- & Mostly & 20 & $74.1 \%$ & & \\
\hline- & Sometimes & 1 & $3.7 \%$ & & \\
\hline- & Rarely & 0 & $0 \%$ & & \\
\hline \multicolumn{6}{|c|}{ Students } \\
\hline \multicolumn{6}{|c|}{ Gender } \\
\hline- & Male & 83 & $28.9 \%$ & 40 & $38.1 \%$ \\
\hline - & Female & 204 & $71.1 \%$ & 65 & $61.9 \%$ \\
\hline \multicolumn{6}{|c|}{ Year group } \\
\hline- & Foundation & 21 & $7.3 \%$ & 4 & $3.8 \%$ \\
\hline- & First & 92 & $32.1 \%$ & 19 & $18.1 \%$ \\
\hline- & Second & 82 & $28.6 \%$ & 54 & $51.4 \%$ \\
\hline- & Third & 24 & $8.4 \%$ & 9 & $8.6 \%$ \\
\hline- & Fourth & 57 & $19.9 \%$ & 19 & $18.1 \%$ \\
\hline- & Postgraduate & 11 & $3.8 \%$ & 0 & $0 \%$ \\
\hline \multicolumn{6}{|c|}{ English as first language? } \\
\hline- & Yes & 208 & $72.59 \%$ & 86 & $81.9 \%$ \\
\hline- & No $\quad$ ) n & 79 & $27.5 \%$ & 19 & $18.1 \%$ \\
\hline \multicolumn{6}{|c|}{ Confidence in using computer technology } \\
\hline- & Always & 84 & $29.3 \%$ & & \\
\hline- & Mostly & 172 & $59.9 \%$ & & \\
\hline- & Sometimes & 28 & $9.8 \%$ & & \\
\hline- & Rarely & 2 & $0.7 \%$ & & \\
\hline- & Never & 1 & $0.3 \%$ & & \\
\hline \multicolumn{6}{|c|}{ Use of social networking websites } \\
\hline- & Regular (>twice a week) & 260 & $90.6 \%$ & & \\
\hline- & Sometimes & 19 & $6.6 \%$ & & \\
\hline- & Rarely (less than once a month) & 1 & $0.3 \%$ & & \\
\hline- & Never & 7 & $2.4 \%$ & & \\
\hline
\end{tabular}


Table 2. Comparison of student preferences for current feedback methods. Data show the number of students that have received each type of feedback $(n=287)$ and their preferred methods; expressed on a scale of 1 to 5 (where 1 was least preferred and 5 was most preferred).

\begin{tabular}{lccc}
\hline Feedback type & $\begin{array}{c}\text { No. of } \\
\text { students } \\
\text { received }\end{array}$ & $\begin{array}{c}\text { Median } \\
\text { preference }\end{array}$ & $\begin{array}{c}\text { Interquartile } \\
\text { range }\end{array}$ \\
\hline $\begin{array}{l}\text { Comments about your work and returned with your } \\
\text { essay/assignment }\end{array}$ & 179 & 5 & 1 \\
$\begin{array}{l}\text { Discussion with lecturer or personal tutor during a one- } \\
\text { to-one meeting }\end{array}$ & 136 & 5 & 1 \\
$\begin{array}{l}\text { Marks given for your work } \\
\text { Comments about your work via email }\end{array}$ & 203 & 4 & 2 \\
$\begin{array}{l}\text { Comments to the class by the lecturer in seminars or } \\
\text { group working sessions }\end{array}$ & 192 & 3 & 1 \\
$\begin{array}{l}\text { General comments to the whole class regarding results } \\
\text { of set work }\end{array}$ & 174 & 3 & 2 \\
$\begin{array}{l}\text { Results of online quizzes/tests } \\
\text { Comments about your work via VLE }\end{array}$ & 161 & 3 & 2 \\
\hline $\begin{array}{l}\text { Comments/suggestions made by a fellow student about } \\
\text { your work }\end{array}$ & 149 & 2 & 2 \\
\hline \begin{tabular}{l} 
Audio and/or video \\
\hline
\end{tabular} & 25 & 2 & 2 \\
\hline
\end{tabular}


Table 3. Showing what students do with their feedback (pre-use); answers for each question on a five-point scale: Always, Mostly, Sometimes, Rarely, Never. The $\mathbf{n}$ values refer to the number of students who responded to each question.

I discuss my feedback with others $(n=286)$ Mostly (39.9\%)

I read through the written feedback more than once Always (41.6\%) $(n=286)$

I go to see the person who set my work to discuss the Sometimes (42.9\%) feedback $(n=280)$ With written feedback, if I get the mark I was expecting, I Always (70.3\%) still read the marker's comments $(n=286)$ If I get feedback after a module has finished, I still find it Mostly (38.7\%) useful $(n=284)$ 
Table 4. Indicating ways in which students made use of their feedback. The $\mathbf{n}$ values represent the number of students that responded to the open question of "how did you make use of your feedback?" and their answers were grouped into categories.

\begin{tabular}{lcc}
\hline & $\begin{array}{c}\text { Pre-use i.e. using } \\
\text { traditional feedback } \\
\text { (n=281) }\end{array}$ & $\begin{array}{c}\text { Post-use i.e. using } \\
\text { video feedback } \\
\text { (n=51) }\end{array}$ \\
\hline To inform future pieces of work & $47.0 \%(132)$ & $43.1 \%(22)$ \\
To understand good/bad points in the & $20.6 \%(58)$ & $15.7 \%(8)$ \\
work it related to/just followed & & \\
instructions & & $9.8 \%(5)$ \\
To improve grades/exam technique/for & $3.2 \%(9)$ & $21.6 \%(11)$ \\
revision & & \\
Have learnt from it in general/gained & $22.4 \%(63)$ & $2.0(1)$ \\
extra knowledge & & $7.8 \%(4)$ \\
\hline Didn't use it & $2.6 \%(13)$ & \\
\hline Other & $2.1 \%(6)$ & \\
\hline
\end{tabular}


Table 5. Students' opinions about the feedback they had received prior to receiving video feedback via the ASSET resource ( $n=287$ for each question). Answers for each question on a five-point scale: Always, Mostly, Sometimes, Rarely, Never.

\begin{tabular}{lc}
\hline & $\begin{array}{c}\text { Most frequent (median) } \\
\text { answer }\end{array}$ \\
\hline The feedback I receive makes clear what I have done well & $\begin{array}{c}\text { Mostly (42.9\%) } \\
\text { Mostly (39.4\%) }\end{array}$ \\
The feedback I receive makes clear what I have done less well & Sometimes (33.4\%) \\
The feedback I receive makes clear how I can improve in the & \\
future & Sometimes (36.2\%) \\
The feedback I receive makes me think differently about how I & \\
work & Mostly (38.0) \\
The feedback I receive helps me work more effectively in later \\
assignments
\end{tabular}


Table 6. Advantages and disadvantages of the use of video in generic feedback provision

as identified by staff and students after using videos in the ASSET resource. The $n$ values

refer to the number of staff/students who responded to an open question and their responses were grouped into categories.

\begin{tabular}{|c|c|}
\hline \multicolumn{2}{|l|}{ Advantages } \\
\hline Staff $(n=8)$ & Students ( $n=105)$ \\
\hline Videos can be re-viewed ( 3 ) & Easy/clear to understand (34) \\
\hline Like a face-to-face session (2) & Accessible/could watch anytime/anywhere (24) \\
\hline Accessible (2) & Could be re-viewed (21) \\
\hline Can use intonation/emphasis to highlight key points (2) & More extensive comments (13) \\
\hline Speed (2) & Can emphasise key points (using intonation) (12) \\
\hline $\begin{array}{l}\text { Students took more notice than other forms of } \\
\text { feedback ( } 2 \text { ) }\end{array}$ & Paid more attention to the feedback (11) \\
\hline Relevant (1) & More personal (11) \\
\hline Can use screencasts to SHOW students what to do (1) & Easy/straightforward (9) \\
\hline Easy to communicate to large groups ( 1 ) & Can aid visualisation (8) \\
\hline Has immediacy of a lecture (1) & Helpful/good instructions (7) \\
\hline \multirow[t]{5}{*}{ Can direct students to the video if they query (1) } & Encourages more staff/student interaction (5) \\
\hline & Removes problems of deciphering handwriting (5) \\
\hline & Better than other forms of feedback (5) \\
\hline & More direct (5) \\
\hline & Other miscellaneous advantages (31) \\
\hline \multicolumn{2}{|l|}{ Disadvantages/challenges } \\
\hline Staff $(n=8)$ & Students $(n=105)$ \\
\hline It took too long (5) & Feedback too generic (18) \\
\hline Getting to grips with the technology (2) & De-personalises the feedback experience (13) \\
\hline Making 'professional' looking videos (2) & Technical problems (13) \\
\hline Difficulty getting students to watch the videos (1) & Slow to load videos/problems buffering (11) \\
\hline Encouraging students to post their own videos (1) & Navigation of ASSET site (10) \\
\hline Time limit on the video (1) & Can't ask questions (10) \\
\hline Making sure the video covers all the issues (1) & Poor video/sound quality (10) \\
\hline Making sure video isn't too brief (1) & Cannot identify any disadvantages (10) \\
\hline Making sure video isn't too impressionistic (1) & Not accessible from the VLE/difficult to access (7) \\
\hline Don't know how the students used it (1) & Have to re-watch whole video if missed a point (6) \\
\hline \multirow[t]{2}{*}{ Lack of VLE integration (1) } & Takes too long to watch videos (6) \\
\hline & Lacking information (6) \\
\hline
\end{tabular}




\section{Research highlights}

- Results from staff and student surveys highlighted problems with feedback provision

- Main issues were timeliness, quality, staff efficiency and student engagement

- The ASSET resource was developed to explore the use of video for feedback provision

- Video enabled the provision of rapid, accessible and engaging, generic feedback

- Most staff and students agreed that video enhanced their feedback experience 